\title{
Energetics, Security and the Sustainable Development of Cities
}

\author{
B. Duchoň, Z. ̌̌́íha* \\ Faculty of Transportation Sciences, Czech Technical University in Prague, Czech Republic \\ *Corresponding author: riha@.fd.cvut.cz
}

DOI: $10.2478 / \mathrm{v} 10158-012-0017-0$

\begin{abstract}
Life in cities and its quality increasingly depends on transport means and on the energy used for their propulsion. A much discussed reason for the substitution of classical energy sources is also energy security; a second reason is the decreasing energetic returnability of oil. This paper draws attention to some aspects connected with accessibility to passenger transport in the city system. It is emphasized that the solution of the abovementioned problems takes into consideration many factors, not only those from the field of transportation. These factors influence one another; therefore it is necessary to find ways how to harmonize these factors for achieving the sustainable development of the city system. The sustainable city development is conditioned by the bearable development of the transport system so that access to various transport modes is ensured for all city inhabitants, and so the sustainable mobility of the city's inhabitants is ensured.
\end{abstract}

KEY WORDS: Energetics, security, sustainable development, city, urban transport, quality.

\section{INTRODUCTION}

Transportation has, during the whole of history, been a basic driver of the form of human society. It determined not only the location of towns, but also their internal form, and, last but not least, it was the basic element of economic development as the inevitable presumption of the barter of goods. Its role in the $21^{\text {st }}$ century will not change and the question is rather in which form we will use transport in the future. The trend of the last few decades (especially the acceleration of car transportation) has shown that one has to solve above all the problems of the transport in cities, to combat the lack of space and also additionally the problem of the energy resource for transport (or the substitution of oil by another resource) whatever the reasons will be - environmental ones (lowering of transport emissions), strategic ones (connected above all with the oil and gas supply security from countries where they are attained), or additional ones (above all the discussed exhaustion of oil during the next 50-100 years).

The environmental impacts of car transport by far concern the cities where the majority people live. Quality urban mass transport and a solution of the propulsion of transport means, in the sense of lower emissions, can thus significantly contribute to the sustainable development of cities and to a higher quality of life.

Urban transport was still developing at the break of the $19^{\text {th }}$ and $20^{\text {th }}$ century in an idyllic way - the urban mass transport had been gradually rising without the serious competition which the individual car transport would become as late as in the course of the $20^{\text {th }}$ century. European cities have been fumbling with the lack of space, as their centres were not designed 
for this type of transport. Besides that it brought a big underflow of revenue for the urban transport companies, as shown in Figure 1.

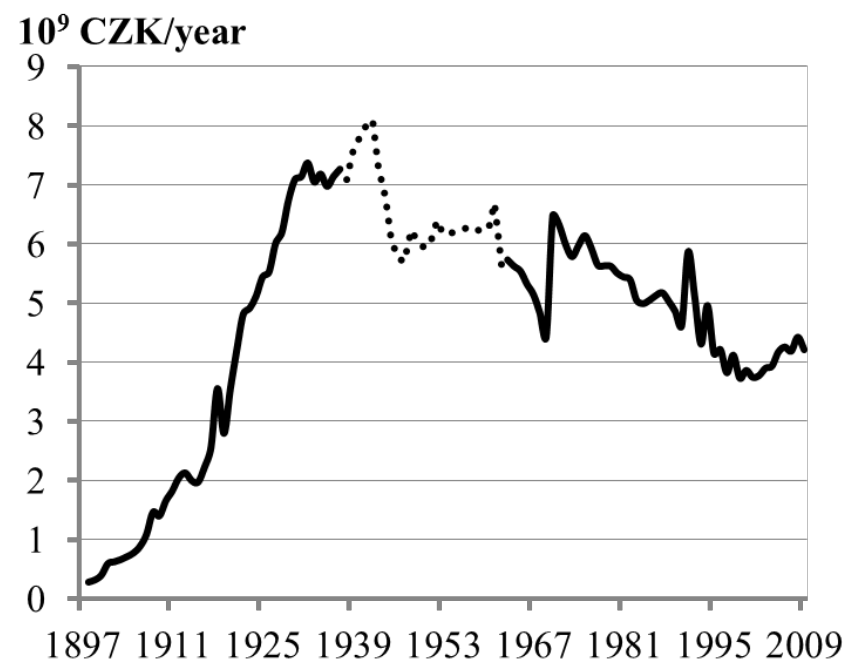

\section{Figure 1: Revenues of the Prague urban transport in the $20^{\text {th }}$ century (real price level 2009, gross estimation 1938-1962).}

(Baroch, 2011)

The graph shows that (excepting the period 1938-1962) the revenue maximum of the Prague urban transport was attained in the thirties of the $20^{\text {th }}$ century, and the revenue has been decreasing during its second half - except for two price rises in 1970 and 1991.

\section{CITY, SYSTEM, TRANSPORT}

The city as a system consists of a number of elements, among which linkages and interactions increase. These elements can be described as follows:

- Activities: products, services, trade, education, culture, travel, and other activities

- Infrastructure: office buildings, residential housing, schools, plants, shops, transport infrastructure-roads, railways, airports, etc.

- Land used for various purposes

- Mobile elements: people, goods, transport means

- Political and social structure: plans, goals, decisions

On the one hand in the city system population activities have been functioning and on another one the economic structure has been created. The action of both these two structures is given by several levels: the national, regional, and urban one. Both structures then create the urban space, where the human activities take place; from the viewpoint of the population these activities can be classified into four categories or factors: work opportunities, production activity and services, the infrastructure use, and the land use. These activities are connected by communication (in a general conception of communication) and the transport system is an implicit component.

To this static conception has to be added the dynamic approach, as the development of the city system has been changing over time both quantitatively and qualitatively. 
The dynamics of changes can relate to central parts of a city when decentralization of activities from this region happens as a consequence of technology changes and criterion economic choice. Outside of this region new residential and office objects appear, new infrastructure springs up. Technical development in the field of transport and communication technologies functions on the city system through two effects. The first one creates a more homogenous land use than in the case of the centralization of activities in the city centre. The second effect makes cities more attractive than small town systems through the building of big commercial, financial, and office centres in big cities.

The economic base has moved from the city centre to suburban regions and this decentralization phenomenon is supported mainly by the development of the car industry and the higher incomes of the inhabitants. Easier access to cars helps then to the higher mobility of the labour force, and so to the further growth of suburban regions. The transport and telecommunication network amplifies the decentralization in the city space.

The big growth in car numbers allows, on the one hand, the high mobility of city inhabitants, but on other hand it strongly influences the city environment and quality of life. In spite of the many approaches trying to harmonize the individual city transport the problems still remain. The question of making public transport more attractive has still failed to be answered by transport strategy and planning. The proposals for public transport support have been eliminated on the other hand by the construction of additional parking areas (land use management), especially through the construction of underground garages in the city centre. This is what one of the approaches to the city system factor integration is connected with. It is city development with respect to the linkage of public transport to the commercial, administrative, and industrial areas, and the harmonization with individual car transport. Taking into account the economic and social factors as the two substantial factors of the city system, the transport supply then constitutes the necessary support of the function of these elements. But, at the same time, transport influences its neighbourhood, and so it is necessary to control other elements of the city system: land use and transport linkage.

City activities are usually considered to be main processes integrating communication and thus also transport services. In this context one needs to choose another approach to the concept of a product or a service, so that economic and social interests are better fulfilled. This problem is dealt with through marketing. The customer chooses the products and services according to their utility. The marketing should thus supply not only the product, but also the whole chain of services, so that the complete supply of the final utility delivery originates including the transport service.

\section{CITY DEVELOPMENT AND TRANSPORT SYSTEM}

The transport demand has the character of a derived demand. This also holds true for the urban transport system. People use their time for the realization of many activities. All these activities have their own particular transport demand functions. These activities are realized within the broad city area. There are commercial, industrial, and residential areas, as well as hospitals, schools, theatres, libraries, and sport areas. But the city area must also take into account the transport activities: the construction of the transport infrastructure as an essential factor of the transport service supply.

However, various people's activities take place at various places at various times of the day. The quality of one man's satisfaction in the city is finally measured by the opportunities to take part in various activities. The result is the demand for city transport. The logical consequence is that the demand is determined by the number of people living in the city area. The wish or need of these people is to get to the specific place 
at the specific time. This is why transport rush hours result at particular moments of the day. These peaks are influenced by the beginnings and ends of work, and with the connected travel to commercial and industrial centres and residential areas. A tension between the supply and demand rises at various times of day.

Various transport modes covering the transport demand create a pressure on the transport infrastructure in various ways. Individual car transport affects the city transport system more vigorously than, for example, bus transport. In addition, various transport means differently influence their neighbourhood. They emit into the environment gaseous exhausts and noise emissions, they cause transport accidents and create traffic congestion. If a city should healthily develop, it must keep a reasonable balance between the demands for the further expansion of activities and for further land use. The consequence of city development is then also the demand for transport development, and therefore the demand for the land use, because the extent and quality of transport supply depends on this development.

Consequently the transport problems are only one of the factors of city development. If public transport can compete with car transport its quality must still be highlighted during the next decades. The service quality criteria include availability, accessibility, information, travel time, customer service, comfort, safety, security, and the environmental impact. If individual car transport is step by step distanced from the city centres by suitable measures (e.g., economic measures, like road tolls), quality public transport must substitute it. In addition to this is the connection with the quest for financial sources, as higher quality also means higher additional costs (e.g., many transport companies converted to low floor busses at the turn of the $20^{\text {th }}$ and $21^{\text {th }}$ century, but they bring with them higher investment and operational costs).

We summarize the basic factors influencing the city development and the transport system:

- Economic activities of a city are usually concentrated in central areas, although many activities often move to suburbs. It always causes congestion as a result of people's demands for travelling to the same place (whether in central or suburban regions) at the same time.

- The deterioration of the environment can be caused by the above-mentioned effects, called externalities, but also by other impacts independent of the transport.

- The accessibility and mobility are the basic conditions of the functioning of a city. The accessibility is to be understood as the possibility of access of the inhabitants to a number of activities through the access to transport. Mobility is to be understood as the ability for movement in the city through the transport system. Mobility can have many limitations: delays caused by congestion, high transport costs, or low revenue of a transport company.

- The losses from public transport can be described partly by the demands for high investment into the transport infrastructure, partly by operation sources. The tariffs often do not cover these high costs and the losses of transport companies therefore rise. The competition of individual car transport and daytime dependent demand increase these losses.

- Social considerations are connected with the question of accessibility and mobility for all city inhabitants.

- The consumption of fuels and energy creates an essential factor of the functioning of the transport system. Nowadays, oil and natural gas supplies are a serious problem, since these commodities have been becoming scarce re-sources. That is why the pressure has been being put on the more effective transport systems with lower energy consumption of transport means all over the world. 


\section{MOBILITY AND ITS CONTROL}

The changes taking place in the post-industrial society towards an information and knowledge society also pressure changes to the city system. These changes can be described by the following linkages and interactions from the viewpoint of the transport system:

- Mobility control with the use of marketing strategies with a complex concept of system elements.

- Implementation of the transport control strategy and area planning with accessibility to transport services.

- Harmonization of the freedom of motion (door-to-door) with the decision-making about infrastructure investments, with the project, real estate, and development decisions, and with the decisions of transport companies ensuring the public transport.

- New marketing approach to commercial, industrial, and administration activities.

- City system management and social responsibility.

The integration of these factors can be ensured through a managerial approach using the control of these factors towards the creation of a network of activities that will ensure a competitive and effective pressure on the support of the city system development with respect not only to economic goals, but also to the social and environmental responsibility.

The concern is in fact the connection or linkage of a city inhabitant or consumer partly with the suppliers of production values (big industrial, commercial, and administration centres), and partly with the suppliers of access routes (operators, deliverers, and other cooperating systems). Control is made so that mainly the strategic and the planning activity leads not only to the local development of fragments with good accessibility, but also that the accessibility to all localities and city system parts is ensured.

\section{ENERGY AND TRANSPORT}

World economics has been facing an increase in crude oil and nature gas prices. Nature gas's price increase is usually rather delayed. The primary resources of energy, both oil and nature gas, represent an essential raw material not only for energy and transport systems, but they also have the large part in the development of other industrial branches. In contrast to the previous crises, we have come across certain opinions and predictions about the termination of the cheap oil and natural gas period. World economics should forget their low prices. It might seem that higher prices signal a lack of oil and natural gas, although this could be false information. The contribution points out numerous factors influencing the price of important energy resources. The combined impact of the supply and demand is in question, as well as the problem of the exhaustion of the above-mentioned resources and the competitiveness of alternative resources, geological and geographical conditions, reliability of the supplies, and, last but not least, the political, social, and terrorist aspects.

Energy remains an important production factor of economic growth. Energy resources must be safe and reliable, environment-friendly, and will have to be sufficient for the future. None of the contemporary energy resources is close to any of these conditions.

The demand depends on the following factors: changes in industrial structure, material changes and substitutions, transport changes, and the development of energy technologies with higher efficiency. These factors can influence the end energy usage in the sectors 
as shown: Civil Engineering (40\%), Industry (30\%), and Transport (30\%). It is supposed that the structure will tend to a higher rate of energy used in transport and still remains based on the combustion of fossil fuels. Primary energy resources are crucial for the next decision process. The condition of sustainable development based on a steady growth of the exploitation of primary resources leads to limited consumption in countries with higher income (energy conservation). Changes in energy production and transformation at a higher efficiency should raise the lower energy consumption in developing countries.

We face two problems: the environmental impacts of fossil fuels, and the possibility to replace these energy sources. Displacing fossil fuels from their current dominate position leads to a discussion of alternative sources based on renewable energy. If we take into account that current fossil fuels cover about $90 \%$ of the total world supply, we can have doubts about any long-term solution. Simply restriction of the use of fossil fuels will generate adequate incentives to develop and use new energy sources, and will create abundant new energy technologies that do not rely on fossil fuels. But it is apparently belief. There are reasons to doubt that changing the relation of prices and thereby the incentives to use fossil fuels will bring forth alternative forms of energy in the amounts required.

The energy crises confirmed that the interest in alternative possibilities always rises when these crises last longer. It was also verified in 1973, when the interest in the use of alternative sources both in energetics and in transportation began to rise. The competitive ability of alternative sources results from the comparison with fossil (non-renewable) energy resources:

- Renewable resources can still not compete with fossil fuels, as their price is lower with respect to their present surplus. But in many cases the possibility of competition exists.

- The use of actual fossil sources has its limitations. One of these limitations is the fear of contribution to emissions towards the greenhouse effect.

- Non-renewable sources are a concentrated form of solar energy.

- In renewable sources solar energy is dispersed.

There exist the following groups of factors that can influence the use of natural gas and oil:

- Essential growth of prices.

- Growth of changes in the environment that can be influenced by the use of fossil fuels as the dominant primary energy source.

- Energetics problem: how to substitute these fossil fuels so that a relatively sufficient amount of these fuels is substituted by other fuels with a corresponding provision for energetic needs.

- Safety risks and crisis situations.

The production of the greenhouse effect with an essential contribution of carbon dioxide and factors influencing the carbon dioxide emissions can be expressed in the macroeconomic equation:

$$
\mathrm{CO}_{2}=\text { POP . h. en. eCO } 2
$$

where $\mathrm{CO}_{2}=$ amount of carbon dioxide emissions; POP = population; $\mathrm{h}=$ GDP per capita; en $=$ energy intensity of the economic system; $\mathrm{eCO}_{2}=$ amount of carbon dioxide on the unit of energy carrier (carbon intensity).

It follows from the equation, that emissions grow with the population growth, with the economic growth, with the high energy set out of the economy and with the high portion of fuels with a high carbon content for the produced energy unit. The high content 
of carbon leads to high carbon dioxide emissions. The population and economic growth will be followed by the growth of emissions.

The emissions can be reduced by:

- reducing energy intensity

- reducing carbon intensity

To decrease the carbon intensity means to move from fossil fuels to fuels with low or no carbon content.

\section{CONCLUSION}

Transport in the $21^{\text {st }}$ century will have to solve the serious problem of energy sources. It is of course a problem as old as mankind itself, that was solved (evidently only temporarily) in the period of the peak industrial revolution, when oil became the ideal product for the propulsion of transport means.

Oil found its fatal use as a motor propulsion source at the turn of the $19^{\text {th }}$ and $20^{\text {th }}$ century. A natural source became an economic one; mankind has known it for long, nevertheless only the technological development caused by the industrial revolution made it possible to use oil in a truly substantial way. In this context we can ask whether we are not also in the same situation in looking for a new energy source for the future, maybe only yet next unknown technologies make it possible to use as fuel in transportation that what we have before eyes now, but we cannot see it.

From the many alternatives to oil no one is sufficiently competitive when we apply to such alternative fuels the four basic requirements - i.e., the technological, energetic, environmental and economic comparability with conventional fuels. From a technology viewpoint not only are the transport means themselves necessary, but also the construction of the infrastructure of the filling stations (in the case of electric cars the charging ones). The next problem of fuels is their energetic characteristics -the rate of the energy gained and used. This rate is most favourable for the energetic commodities which have the basic advantage of offering a large amount of energy in a low volume of commodity. In the case of oil this rate was best during the beginning of its use, but it has gradually been decreasing with the worsening of its extraction conditions.

Electricity, meanwhile, puts itself forward as a possible substitution for the classical fuels in transportation. It is nothing new; the use of it as a means of transport propulsion was already debated at the beginning of the $20^{\text {th }}$ century. Today this idea has returned, also with respect to a technological shift above all in the development of accumulators. Today's accumulators can be recharged to $60 \%$ in 15 minutes again (on the other hand it decreases the battery lifespan). Of course, the problem with electric cars remains the distance that they can travel after one charging and other running features. That is why their use is expected first in cities, where there are enough possibilities for charging (overnight or at the workplace). As for energy sources, not only classical ones can be used, but also local ones, e.g., wind or solar energy.

\section{AKNOWLEDGEMENTS}

This paper originated as a part of a CTU in Prague, Faculty of Transportation Sciences research project on Design and Operation Networks - Optimization Methods Development (MSM: 6840770043), financed by the Ministry of Education, Youth and Sports of CR. 


\section{REFERENCES}

Baroch, V., 2011. The key to the prosperity of a city is also the clear funding of the urban public transport. Moderní obec, no. 2. (in Czech)

Duchoň, B., 2004. Transport, Energy, Fuels and the Environment. In Approaches to Assessing the Environment. Prague: Charles University Environment Center.

Duchoň, B., 2005. Transport System and Sustainable Development. In 3rd International SIIV Congress. Bari: SIIV.

Duchoň, B., 2006. Biomass in the Czech Republic, Energy and Transport Sector. In $1^{\text {st }}$ Workshop on Energy Economics and Technology. Dresden: Dresden University of Technology.

Duchoň, B., Říha, Z. et al., 2007. Economics of Introducing of Alternative Fuels in Transport and the Possibilities of Internalization of External Cost in Czech Republic. Prague: Ministry of Transport of the Czech Republic. 